\title{
Impact of decompression of the right ventricle on the sinusoidal communications in pulmonary atresia and intact ventricular septum
}

Takahiro Eitoku, MD, PhD, ${ }^{\mathrm{a}}$ Shingo Kasahara, $\mathrm{MD}, \mathrm{PhD},{ }^{\mathrm{b}}$ Kenji Baba, MD, PhD, ${ }^{\mathrm{a}}$ and Yasuhiro Kotani, $\mathrm{MD}, \mathrm{PhD}^{\mathrm{b}}$

Feature Editor's Introduction-Surgical management of children with pulmonary atresia and intact ventricular septum remains challenging. These patients have a large spectrum of pathological anatomy, including various degrees of coronary to right ventricular $(R V)$ fistulous connections, culminating in the true $R V$ coronary artery dependence. A surgical group from Okayama led by $\mathrm{Dr}$ Yasuhiro Kotani presents their experience with these challenging patients and discusses the indications, role, timing, and impact of $R V$ decompression.

\section{Igor E. Konstantinov, MD, PhD, FRACS}

Coronary artery anomalies, namely, sinusoidal communications (SC), are commonly seen in patients with pulmonary atresia and intact ventricular septum (PA-IVS), especially in those with a diminutive right ventricle (RV). ${ }^{1}$ Therefore, assessment of the coronary arteries is essential before any interventions that could potentially reduce the RV pressure in patients with a relatively smaller RV, especially when the outlet portion is absent because SCs tend to be large. ${ }^{1}$ Several reports from the 1990s demonstrated that a large SC with a stenosis in the proximal portion of the left coronary artery (LCA) carried a high risk of death..$^{2-4}$ Since then, it has been considered that RV cannot safely be decompressed in this circumstance. Furthermore, the continued presence of coronary perfusion with unsaturated RV blood could lead to myocardial fibrosis, resulting in arrhythmia and myocardial ischemia.

\section{WHAT HAPPENS WHEN THE RIGHT VENTRICLE IS DECOMPRESSED? \\ Right Ventricle Growth After Decompression}

Decompression of the RV (RVD) through pulmonary valvotomy was considered as an optimal treatment for those

From the ${ }^{\mathrm{a}}$ Pediatrics and ${ }^{\mathrm{b}}$ Cardiovascular Surgery, Okayama University Graduate School of Medicine, Dentistry, and Pharmaceutical Sciences and Okayama University Hospital, Okayama, Japan.

Received for publication May 29, 2021; revisions received Aug 4, 2021; accepted for publication Aug 23, 2021; available ahead of print Sept 16, 2021.

Address for reprints: Yasuhiro Kotani, MD, PhD, 2-5-1 Shikata, Okayama, Japan 7008558 (E-mail: yasuhiro.kotani@cc.okayama-u.ac.jp).

J Thorac Cardiovasc Surg 2022;163:2210-5

$0022-5223 / \$ 36.00$

Copyright (c) 2021 by The American Association for Thoracic Surgery

https://doi.org/10.1016/j.jtcvs.2021.08.083

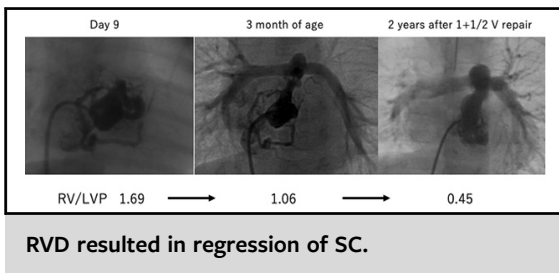

CENTRAL MESSAGE

RVD should be an option for treatment in patients with pulmonary atresia and intact ventricular septum unless the coronary circulation is RV dependent.

See Commentary on page 2216.

with a reasonably sized $\mathrm{RV}$ in the $1950 \mathrm{~s} \cdot{ }^{5-7}$ For those with a tight outlet portion, the combination of repair of the right ventricular outflow tract (RVOT) and construction of a systemic-to-pulmonary arterial shunt has been the mainstay of surgical interventions since its first report in 1971 until today. ${ }^{6,8}$ The indications have been considerably refined as our knowledge of the anatomic complexities, together with their correlation to physiology, has grown. However, various controversies remain regarding the indications for RVD. It is still unresolved whether a procedure on the RVOT should be performed in all cases, even when the RV is diminutive, except in cases of right ventricular dependent coronary circulation (RVDCC). Previous reports demonstrated several advantages of RVD in patients with PA-IVS, and one of the important effects is RV growth and subsequent biventricular repair. ${ }^{8,10-12}$ An early study looking at the impact of RVD in 22 patients who underwent transventricular pulmonary valvotomy demonstrated that the RV end-diastolic volume increased from $59.1 \% \pm 39.3 \%$ of the predicted normal before the initial surgery to $114.6 \% \pm 63.2 \%$ at late follow-up catheterization, resulting in the achievement of biventricular repair in more than $90 \% .^{12}$ Several studies have emphasized the importance of RV myectomy ${ }^{13}$ or RV overhaul $^{8,11,14}$ in addition to RVD, which recruited 
approximately $60 \%$ to $87 \%$ of patients who achieved a biventricular repair. This result can be altered depending on the severity of hypoplasia of the RV or the tricuspid valve (TV) at birth.

\section{Coronary Artery Anatomy-Based Strategy for Decompression of the Right Ventricle}

Large SC and RVDCC occur most frequently in patients with the smallest RVs, although there are cases when RVDCC is found in patients with a normal RV size. ${ }^{15}$ It is universally agreed that a treatment strategy can be constructed on the basis of the understanding of coronary artery circulation. $^{2,16}$ Fontan operation is usually planned for patients whose coronary artery circulation is entirely or largely dependent on the RV, and we do not attempt to decompress by surgical/catheter-based intervention or thromboexclusion of the RV. ${ }^{4,17}$ At the time of the Fontan procedure, the RV should be incorporated into the repair to receive oxygenated blood from the left atrium. However, it is important to note that persistent RV hypertension with the presence of SCs potentially leads to the progression of coronary abnormalities such as stenosis, ectasia, and interruptions that can lead to sudden death. A multicenter study from Australia and New Zealand showed that RVDCC was associated with myocardial ischemia and sudden death after Fontan operation. ${ }^{18}$ Another key finding of this study is that the occurrence of angina (16\%) is not negligible, which makes us think we should somehow intervene to decompress the RV even in patients having Fontan operation (decompression Fontan), so that coronary-related complications could be avoided. For patients in whom a relatively small and distal portion of the coronary artery circulation is $\mathrm{RV}$ dependent, one can consider proceeding to a biventricular repair, depending on the size of the RV and TV.

\section{Impact of Decompression of the Right Ventricle on Sinusoidal Communications}

The impact of RVD on SC has been discussed since a few decades ago when decompression was considered as an optimal palliation for those with a reasonable RV size. ${ }^{2,19,20}$ In contrast, the natural history of SC is not well elucidated, whether or not this may progress, persist, or regress. $^{20}$ In 1974, Freedom and Harrington ${ }^{21}$ described that $\mathrm{SC}$ regressed when the RV pressure declined by means of pulmonary valvotomy and infundibulectomy. However, RVD has been considered as "taboo" after further recognition of the anatomic and physiologic characteristics of SC, especially in those with large SCs at the proximal or midportion of the fistula compared with distal and apical. ${ }^{4,22-24}$ In children with RVDCC, RVD leads to a decrease in the intracavitary RV pressure, which subsequently leads to a decrease in the blood supply to the dependent myocardium. Critical myocardial ischemia is caused by the venous blood from the RV that supplies the myocardium. Therefore, RVD is contraindicated in children with RVDCC. Giglia and colleagues ${ }^{2}$ investigated 26 patients with various degrees of SC and concluded that RVD can be safely performed unless stenosis or occlusion is present in both the left ventricle (LV) and RV, namely, RVDCC. Previous authors have advocated RVD, either performed retrogradely by tricuspid valve excision ${ }^{25}$ or by the placement of an RVOT patch. ${ }^{26}$ However, these approaches might also cause or increase myocardial ischemia, because the decompressed RV would then offer increased blood flow during diastole, which would probably cause further distal ischemia, as described by Giglia and colleagues. ${ }^{2}$ For this reason, RVD is recommended in the absence of large SCs because this may promote growth of the RV. ${ }^{19,25}$

\section{HOW DO WE DECOMPRESS THE RIGHT VENTRICLE? \\ Surgical Pulmonary Valvotomy}

After transpulmonary valvotomy was introduced, ${ }^{9}$ RVD by means of surgical pulmonary valvotomy was widely used in the 1990s. ${ }^{8}$ Surgical valvotomy under cardioplegic arrest is the most reliable technique responsible for creating the optimal size of the communication between the RV and pulmonary artery. However, it is important to note that a cardioplegic arrest or even temporary pressure unloading of the RV by cardiopulmonary bypass can pose a risk for myocardial ischemia in patients with a large SC. We experienced a case with a large SC to the LCA and right coronary artery who developed severe LV dysfunction after surgical valvotomy under cardioplegic arrest. The patient recovered 3 days later and subsequently underwent Fontan operation, but inadequate myocardial protection or decrease in RV pressure during cardiopulmonary bypass was considered as a cause of LV dysfunction, and no further RVD was attempted during staged palliation. Our early experience showed a favorable outcome by means of off-pump pulmonary valvotomy with BTS through left thoracotomy. ${ }^{11,14}$ This is technically a demanding surgery, but it makes sense to patients with SC because it can avoid the use of cardiopulmonary bypass. Moreover, it is technically difficult to create a larger communication; thus, there is a lower chance of myocardial ischemia intraoperatively. How big is communication big enough to decompress RV? Our experience indicates that 2 to $4 \mathrm{~mm}$ should be sufficient in neonates. ${ }^{11,14}$

\section{Transcatheter Pulmonary Valvotomy}

Successful transcatheter pulmonary valvotomy of the RVOT was introduced by the Toronto team in the early 1990s, and this approach has become the treatment of choice in many centers for patients with a good-sized RV with a membranous atresia of the pulmonary valve. ${ }^{27}$ Indications for catheter valvotomy include mild hypoplasia of the RV, that is, potential biventricular candidate, patent 
outlet portion, valvular atresia, confluent pulmonary arteries, and no RVDCC. ${ }^{10,28}$ However, the influence of catheter valvotomy in a single ventricle, namely, severe hypoplasia of the RV, is not well described. The advantage of transcatheter valvotomy is that it can avoid coronary ischemia related to cardioplegic arrest during open surgery because RV/LV pressure can be monitored during the procedure. In contrast, there is a disadvantage of perforation of the RV outflow, resulting in cardiac tamponade. Successful perforation rates range from $70 \%$ to $100 \%$, and periprocedural mortality in the largest published series to date is consistently $5 \%$ to $15 \% .{ }^{29,30}$ Patients with a tight outlet portion may require surgical intervention, such as Blalock-Taussig (BT) shunt, due to inadequate antegrade pulmonary blood flow or recurrent RVOT obstruction.

\section{OUR STRATEGY FOR RIGHT VENTRICLE DECOMPRESSION AND ITS INFLUENCE ON SINUSOIDAL COMMUNICATIONS}

Figure 1 shows our strategy for RVD. Our strategy includes RVD whenever possible from the first palliation. ${ }^{11}$ Transarterial surgical pulmonary valvotomy is performed with a modified BTS at the first palliation. The size of communication between the RV and pulmonary artery is 3 to $4 \mathrm{~mm}$ in neonates as for the target of RV/LV pressure less than 1.0, when no SC was present. In patients with $\mathrm{SC}$, the communication is adjusted to approximately $2 \mathrm{~mm}$ to achieve $\mathrm{RV} / \mathrm{LV}$ pressure 1.0 or greater. For patients with a large SC to LCA, the RV/LV pressure is kept greater than 1.0. RVD is postponed until second or third palliation when the patients have a tight/no outlet portion not suitable for pulmonary valvotomy in the neonatal period (Figure 2). Patients are routinely assessed for RV pressure, RV size, and coronary anatomy/flow direction every 3 to 6 months during the first 2 years of life, as we believe that this is a crucial period for patients if the RV pressure, coronary fistula, and RV size change. Multistaged RVD by catheter and surgical intervention is performed, which causes the RV/LV pressure to gradually decrease over time, resulting in SC not demonstrated by RV angiography at the definitive repair (Figure 3). Our experience showed that in 23 patients who had SC at birth, SC regressed after multistaged decompression in 12 patients $(52 \%)$, including 8 patients whose fistulas completely disappeared. ${ }^{11}$ Absolute contraindications for RVD include RVDCC (Figure 4). For patients with RVDCC with total coronary atresia with progressive myocardial ischemia, that is, ST change with or without hemodynamic instability and arrhythmia, aortic to RV shunt has been previously described. ${ }^{31,32}$ This is the most difficult group of patients with PA-IVS, and patients may not survive without

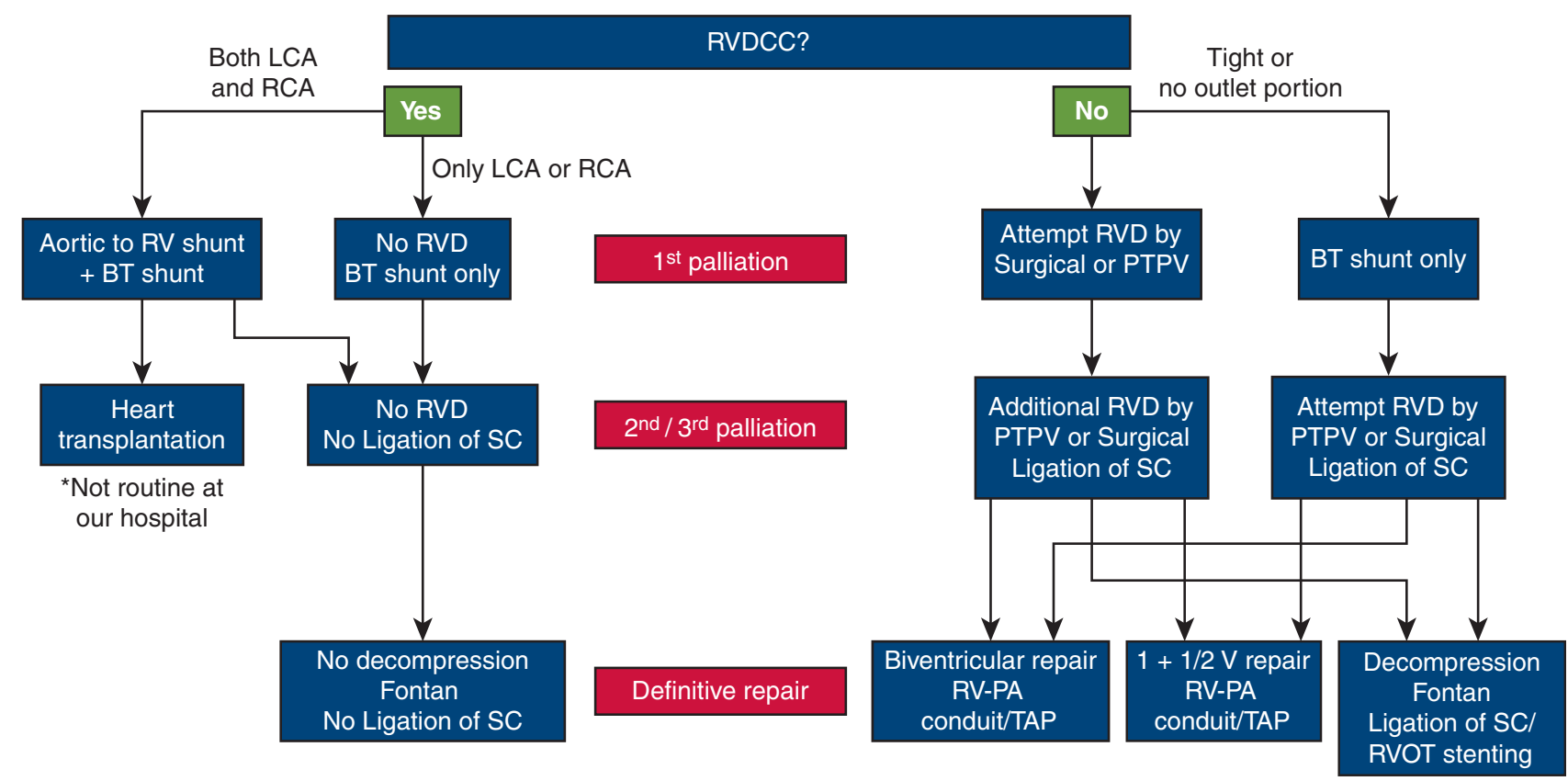

FIGURE 1. Strategy for decompression of the RV. Coronary artery anatomy is assessed upon the diagnosis of PA-IVS. Patients without RVDCC undergo surgical pulmonary valvotomy at first palliation. In patients with a tight outlet portion/bipartite RV, RVD is postponed until second/third palliation. Multiple catheter/surgical intervention is planned when the communication between RV and pulmonary artery becomes narrow. For patients undergoing Fontan operation, RVOT stenting or ligation of SC is considered to achieve "decompression Fontan." RVDCC, Right ventricular dependent coronary circulation; $L C A$, left coronary artery; $R C A$, right coronary artery; $R V$, right ventricle; $B T$, Blalock-Taussig; $R V D$, decompression of the right ventricle; $P T P V$, percutaneous transcatheter pulmonary valvotomy; $S C$, sinusoidal communications; $R V-P A$, right ventricle-to-pulmonary artery; $T A P$, transannular patch; $R V O T$, right ventricular outflow tract. 

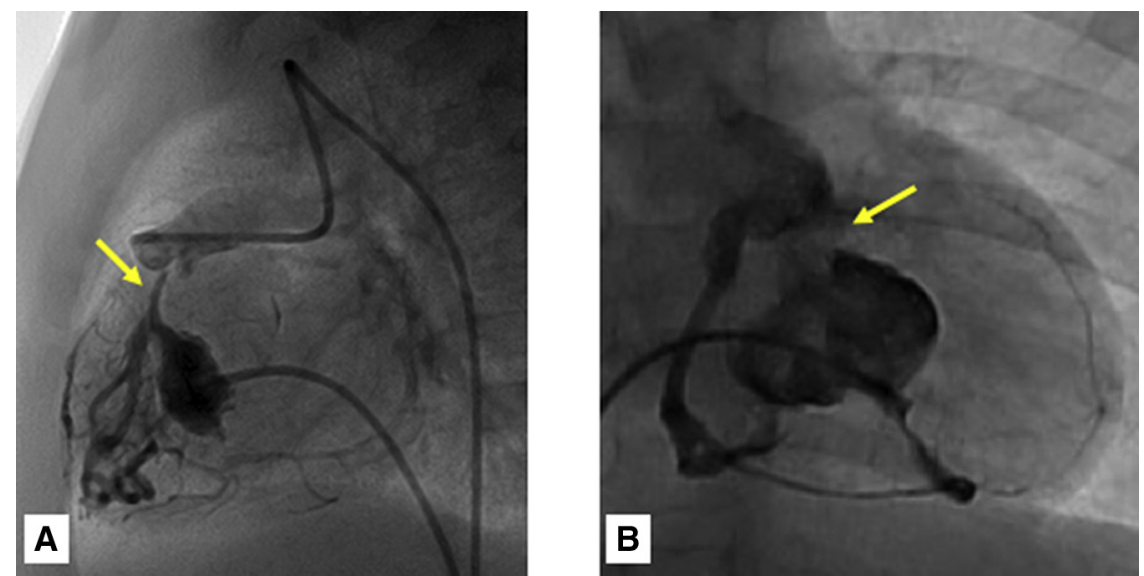

FIGURE 2. Right ventriculography in patient with a tight/no outlet portion. Right ventriculography shows (A) rudimentary tight outlet portion (arrow) and (B) no outlet portion, that is, bipartite RV (arrow).

intervention. Aortic to RV shunt with either direct anastomosis to $\mathrm{RV}^{31}$ or anastomosis to tricuspid valve ${ }^{32}$ prevents coronary ischemia and works as a bridge to heart transplantation or the Fontan pathway. For those without any evidence of myocardial ischemia, even RVDCC with total coronary atresia, the indication for aortic to RV shunt is not well discussed. We had a patient with total coronary atresia (Figure 4, $C$ and $D$ ), who did not have any signs of myocardial ischemia in the first weeks of life. The decision was made to perform only a modified BT shunt. The patient tolerated the procedure well and went home, but died of respiratory infection 3 months later. However, we do not have a clear answer that this patient deteriorated because of myocardial ischemia due to an untreated RVDCC. Patients without an outlet portion of the RV were considered to have difficulty decompressing the RV even without RVDCC. We included 6 patients without an outlet portion of the RV and 5 patients who underwent Fontan completion, except 1 with $1+1 / 2$ ventricular repair. Patients with a huge SC to LCA are at a high risk of myocardial ischemia, and RVD is considered only if the shunt flow can be restricted by surgical ligation of the fistula. Ligation of the fistula has been described by Foker and colleagues. ${ }^{33}$ We ligate the fistula when the patients present with a huge SC without aortocoronary atresia. Coronary/RV angiography with a balloon occlusion test of SC can be considered in cases of coronary ischemia brought about by the ligation of the fistula due to atresia or stenosis at the proximal portion of the coronary artery where SC drains into. However, this does not always exclude the possibility of coronary ischemia upon ligation of the $\mathrm{SC}$ as a balloon occlusion test is often technically difficult and unreliable. For the technical aspect of fistula ligation, the communication between the coronary artery and RV is usually well identified from the epicardial side as its caliber changes. An epicardial echocardiogram also helps to show the communication site. A pair or 2 interrupted Prolene sutures with a pledget are used to close the communication. Ligation is usually performed at the Glenn shunt, as we think patients post-BTS are hemodynamically unstable due to parallel circulation, and to avoid a sudden change in coronary flow by the ligation, which may be influenced by the physiology of the BT shunt. For patients undergoing Fontan operation, we attempt to ligate the SC or RVOT reconstruction/stenting RVOT whenever technically feasible to achieve "decompression Fontan." The indication of decompression Fontan includes no RVDCC, similar to the indication for RVD. However, careful attention should be given to patients with a large SC to LCA who do not assess

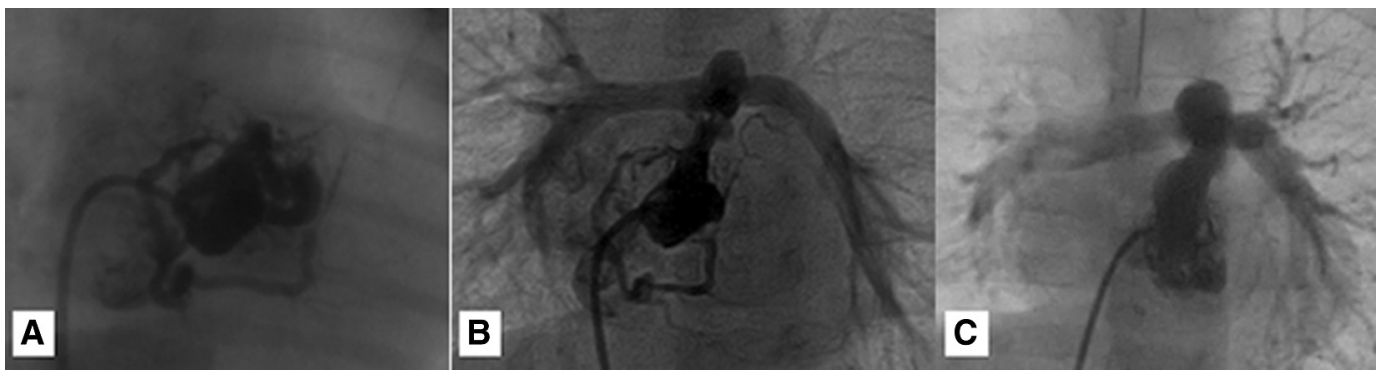

FIGURE 3. Staged decompression of the RV and change in SC. A, Day 9-SC seen and RV/LV pressure was 1.69. B, Three months of age-SC still seen, $\mathrm{RV} / \mathrm{LV}$ pressure decreased to 1.06. C, Two years after 1+1/2 ventricular repair-no SC demonstrated, RV/LV pressure was 0.45 . 

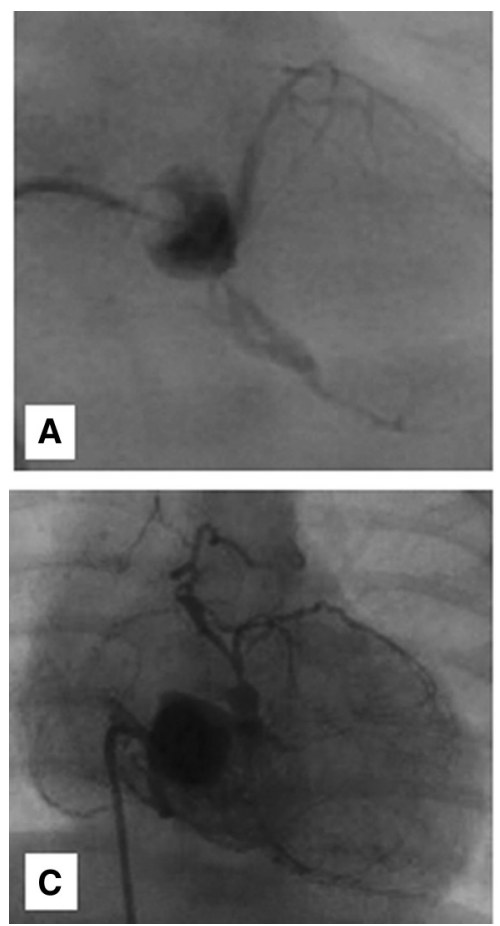
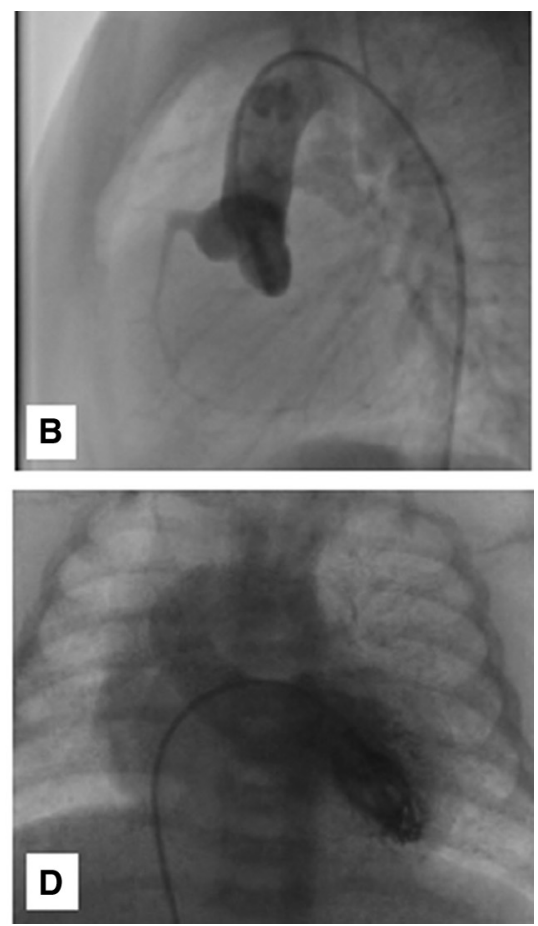

FIGURE 4. RV-dependent coronary circulation in 2 patients. Patient 1 had a monopartite RV (A) with atresia of proximal segment of the LCA (B). Patient 2 had had a monopartite RV (C) with atresia of proximal segments of both coronary arteries (D).

the details of coronary/SC anatomy with a balloon occlusion test, as it cannot exclude the possibility of coronary ischemia when RV is decompressed. There is no universal agreement as to whether RV should be decompressed in patients with diminutive RV who are undergoing Fontan palliation, because concerns still remain about myocardial ischemia when there is a sudden change in the coronary flow upon the RVD, especially in those with a large SC and stenosis at the proximal coronary arteries. The long-term effects of RVD in Fontan circulation are still unknown, and careful follow-up is necessary.

\section{CONCLUSIONS}

There is no doubt that RVD facilitates RV growth in patients with a decent RV size without a large SC. Our experience demonstrated that it would be safe to decompress the $\mathrm{RV}$ if the RV pressure is kept at least equal to the LV pressure. Further decompression can be achieved by multistaged intervention, because this gentle, stepwise decompression does not seem to compromise the coronary perfusion. Although the exact mechanisms are unknown, we believe that the regression of SC will reduce the risk of coronary-related complications. Therefore, a long-term follow-up is necessary.

\section{Conflict of Interest Statement}

The authors reported no conflicts of interest.

The Journal policy requires editors and reviewers to disclose conflicts of interest and to decline handling or reviewing manuscripts for which they may have a conflict of interest. The editors and reviewers of this article have no conflicts of interest.

\section{References}

1. Daubeney PEF, Delany DJ, Anderson RH. Pulmonary atresia with intact ventricular septum: range of morphology in a population-based study. ACC Curr J Rev. 2002;11:90.

2. Giglia TM, Mandell VS, Connor AR, Mayer JE, Lock JE. Diagnosis and management of right ventricle-dependent coronary circulation in pulmonary atresia with intact ventricular septum. Circulation. 1992;86:1516-28.

3. Coles JG, Freedom RM, Lightfoot NE, Dasmahapatra HK, Williams WG, Trusler GA, et al. Long-term results in neonates with pulmonary atresia and intact ventricular septum. Ann Thorac Surg. 1989;47:213-7.

4. Williams WG, Burrows P, Freedom RM, Trusler GA, Coles JG, Moes CA, et al. Thromboexclusion of the right ventricle in children with pulmonary atresia and intact ventricular septum. J Thorac Cardiovasc Surg. 1991;101:222-9.

5. Cole RB, Muster AJ, Lev M, Paul MH. Pulmonary atresia with intact ventricular septum. Am J Cardiol. 1968;21:23-31.

6. Bowman FO, Malm JR, Hayes CJ, Gersony WM, Ellis K. Pulmonary atresia with intact ventricular septum. J Thorac Cardiovasc Surg. 1971;61:85-95.

7. Moulton AL, Bowman FO, Edie RN, Hayes CJ, Ellis K, Gersony WM, et al. Pulmonary atresia with intact ventricular septum. J Thorac Cardiovasc Surg. 1979; 78:527-36.

8. Pawade A, Capuani A, Penny DJ, Karl TR, Mee RBB. Pulmonary atresia with intact ventricular septum: surgical management based on right ventricular infundibulum. J Card Surg. 1993;8:371-83.

9. de Leval M, Bull C, Stark J, Anderson RH, Taylor JF, Macartney FJ. Pulmonary atresia and intact ventricular septum: surgical management based on a revised classification. Circulation. 1982;66:272-80.

10. Ovaert C, Qureshi SA, Rosenthal E, Baker EJ, Tynan M. Growth of the right ventricle after successful transcatheter pulmonary valvotomy in neonates and infants with pulmonary atresia and intact ventricular septum. J Thorac Cardiovasc Surg. 1998;115:1055-62.

11. Kotani Y, Kasahara S, Fujii Y, Eitoku T, Baba K, Otsuki S, et al. A staged decompression of right ventricle allows growth of right ventricle and subsequent 
biventricular repair in patients with pulmonary atresia and intact ventricular septum. Eur J Cardiothorac Surg. 2016;50:298-303.

12. Shaddy RE, Sturtevant JE, Judd VE, McGough EC. Right ventricular growth after transventricular pulmonary valvotomy and central aortopulmonary shunt for pulmonary atresia and intact ventricular septum. Circulation. 1990;82(5 Suppl): IV157-63.

13. Bryant R, Nowicki ER, Mee RB, Rajeswaran J, Duncan BW, Rosenthal GL, et al. Success and limitations of right ventricular sinus myectomy for pulmonary atresia with intact ventricular septum. J Thorac Cardiovasc Surg. 2008;136: 735-42.e2.

14. Sano S, Ishino K, Kawada M, Fujisawa E, Kamada M, Ohtsuki S. Staged biventricular repair of pulmonary atresia or stenosis with intact ventricular septum. Ann Thorac Surg. 2000;70:1501-6.

15. Mair DD, Julsrud PR, Puga FJ, Danielson GK. The Fontan procedure for pulmonary atresia with intact ventricular septum: operative and late results. J Am Coll Cardiol. 1997;29:1359-64.

16. Gentles TL, Colan SD, Giglia TM, Mandell VS, Mayer JEJ, Sanders SP. Right ventricular decompression and left ventricular function in pulmonary atresia with intact ventricular septum. The influence of less extensive coronary anomalies. Circulation. 1993;88(5 Pt 2):II183-8.

17. Waldman JD, Lamberti JJ, Mathewson JW, George L. Surgical closure of the tricuspid valve for pulmonary atresia, intact ventricular septum, and right ventricle to coronary artery communications. Pediatr Cardiol. 1984;5:221-3.

18. Elias P, Poh CL, du Plessis K, Zannino D, Rice K, Radford DJ, et al. Long-term outcomes of single-ventricle palliation for pulmonary atresia with intact ventricular septum: Fontan survivors remain at risk of late myocardial ischaemia and death. Eur J Cardiothorac Surg. 2018;53:1230-6.

19. Patel RG, Freedom RM, Moes CA, Bloom KR, Olley PM, Williams WG, et al. Right ventricular volume determinations in 18 patients with pulmonary atresia and intact ventricular septum. Analysis of factors influencing right ventricular growth. Circulation. 1980;61:428-40.

20. Waldman JD, Karp RB, Lamberti JJ, Sand ME, Ruschhaupt DG, Agarwala B. Tricuspid valve closure in pulmonary atresia and important RV-to-coronary artery connections. Ann Thorac Surg. 1995;59:933-41.

21. Freedom RM, Harrington DP. Contributions of intramyocardial sinusoids in pulmonary atresia and intact ventricular septum to a right-sided circular shunt. Heart. 1974;36:1061-5.

22. Najm HK, Williams WG, Coles JG, Rebeyka IM, Freedom RM. Pulmonary atresia with intact ventricular septum: results of the Fontan procedure. Ann Thorac Surg. 1997;63:669-75.

23. O'Connor WN, Cottrill CM, Johnson GL, Noonan JA, Todd EP. Pulmonary atresia with intact ventricular septum and ventriculocoronary communications: surgical significance. Circulation. 1982;65:805-9.
24. Gittenberger-de Groot AC, Sauer U, Bindl L, Babic R, Essed CE, Bühlmeyer K. Competition of coronary arteries and ventriculo-coronary arterial communications in pulmonary atresia with intact ventricular septum. Int J Cardiol. 1988 18:243-58.

25. Hawkins JA, Kent Thorne J, Boucek MM, Orsmond GS, Ruttenberg HD, Veasy LG, et al. Early and late results in pulmonary atresia and intact ventricular septum. J Thorac Cardiovasc Surg. 1990;100:492-7.

26. Squitieri C, di Carlo D, Giannico S, Marino B, Giamberti A, Marcelletti C Tricuspid valve avulsion or excision for right ventricular decompression in pulmonary atresia with intact ventricular septum. J Thorac Cardiovasc Surg. 1989; 97:779-84.

27. Justo RN, Nykanen DG, Williams WG, Freedom RM, Benson LN. Transcatheter perforation of the right ventricular outflow tract as initial therapy for pulmonary valve atresia and intact ventricular septum in the newborn. Cathet Cardiovasc Diagn. 1997;40:408-13.

28. Alwi M. Management algorithm in pulmonary atresia with intact ventricular septum. Catheter Cardiovasc Interv. 2006;67:679-86.

29. Alwi M, Choo K-K, Radzi NAM, Samion H, Pau K-K, Hew C-C. Concomitan stenting of the patent ductus arteriosus and radiofrequency valvotomy in pulmonary atresia with intact ventricular septum and intermediate right ventricle: early in-hospital and medium-term outcomes. J Thorac Cardiovasc Surg. 2011;141: 1355-61.

30. Lamers L, Garn B, Ellsworth E, Graziano JN. Decreased incidence of rightventricular outflow tract complications using a retrograde snare technique for radiofrequency pulmonary valve perforation. Pediatr Cardiol. 2012;33: 1275-80.

31. Sakurai H, Sakurai T, Ohashi N, Nishikawa H. Aortic to right ventricular shunt for pulmonary atresia with intact ventricular septum and bilateral coronary ostial atresia. J Thorac Cardiovasc Surg. 2018;156:e17-20.

32. Said SM, Marey G, Greene R, Griselli M, Hiremath G, Aggarwal V, et al. The double shunt technique as a bridge to heart transplantation in a patient with pulmonary atresia with intact septum and right ventricular-dependent coronary circulation. JTCVS Tech. 2021;7:216-21.

33. Foker JE, Setty SP, Berry J, Jain P, Catton K, Gittenberger-de-Groot AC, et al Treatment of right ventricle to coronary artery connections in infants with pulmonary atresia and intact ventricular septum. J Thorac Cardiovasc Surg. 2008;136 $749-56$.

Key Words: decompression of the right ventricle, pulmonary atresia and intact ventricular septum, sinusoidal communications 